\title{
Biogeography of cyclamen: an application of phyloclimatic modelling
}

Book or Report Section

Published Version

Yesson, C. and Culham, A. (2011) Biogeography of cyclamen: an application of phyloclimatic modelling. In: Hodkinson, T., Jones, M., Waldren, S. and Parnell, J. (eds.) Climate change, ecology and systematics. Cambridge University Press, pp. 265-279. ISBN 9780521766098 (Chapter 12) Available at https://centaur.reading.ac.uk/20418/

It is advisable to refer to the publisher's version if you intend to cite from the work. See Guidance on citing.

Publisher: Cambridge University Press

All outputs in CentAUR are protected by Intellectual Property Rights law, including copyright law. Copyright and IPR is retained by the creators or other copyright holders. Terms and conditions for use of this material are defined in the End User Agreement.

\section{www.reading.ac.uk/centaur}

\section{CentAUR}

Central Archive at the University of Reading 
Reading's research outputs online 


\title{
12
}

\section{Biogeography of Cyclamen: an application of phyloclimatic modelling}

\author{
C. Yesson \\ Institute of Zoology, Zoological Society of London, UK \\ A. Culham \\ School of Biological Sciences and The Walker Institute for Climate Change, \\ University of Reading, UK
}

\begin{abstract}
Cyclamen is a genus of popular garden plant, protected by Convention on International Trade in Endangered Species (CITES) legislation. Many of its species are morphologically and phenologically adapted to the seasonal climate of the Mediterranean region. Most species occur in geographic isolation and will readily hybridise with their sister species when brought together. We investigate the biogeography of Cyclamen and assess the impact of palaeogeography and palaeoclimate change on the distribution of the genus. We use techniques of phyloclimatic modelling (combining ecological niche modelling and phylogenetic character optimisation) to investigate the heritability of climatic preference and
\end{abstract}

Climate Change, Ecology and Systematics, ed. Trevor R. Hodkinson, Michael B. Jones, Stephen Waldren and John A. N. Parnell. Published by Cambridge University Press.

(C) The Systematics Association 2011. 
to reconstruct ancestral niches. Conventional and phyloclimatic approaches to biogeography are compared to provide an insight into the historic distribution of Cyclamen species and the potential impact of climate change on their future distribution. The predicted climate changes over the next century could see a northward shift of many species' climatic niches to places outside their current ranges. However, such distribution changes are unlikely to occur through natural antbased dispersal, so conservation measures are likely to be required.

\subsection{Introduction}

\subsubsection{Cyclamen: present-day status and distribution}

Cyclamen $\mathrm{L}$. is a genus of $c .20$ species in the family Myrsinaceae. Its species are perennial herbs, having distinctive flowers with reflexed petals, that are often scented, and winter blooming. These characteristics make Cyclamen a popular garden plant. Its popularity has prompted many studies on the group, including cytology (Bennett and Grimshaw, 1991; Anderberg, 1994), hybridisation (Gielly et al., 2001; Grey-Wilson, 2003) and phenology (Debussche et al., 2004). There are several phylogenetic studies based on morphological and molecular data (Anderberg et al., 2000; Clennett, 2002; Compton et al., 2004; Yesson et al., 2009). Although these studies present similar findings for many sister species pairings, they do not agree on the complete phylogenetic topology. Some uncertainty remains regarding subgeneric relationships and species delimitation.

Cyclamen is a phenologically interesting genus; in any month of the year, at least one species can be found flowering somewhere (Grey-Wilson, 2003), which is an unusual trait for such a small group, limited to boreal, seasonal climates around the Mediterranean basin. Its highest diversity is found in Turkey (11 species) and Greece (at least five species - Culham et al., 2009) (Fig 12.1). The seasonal winterwet, summer-dry climate of this region is thought to be an important factor in the speciation of Cyclamen. Many species are adapted to a Mediterranean-type climate and die back to an underground organ during the dry summer months (Debussche et al., 2004).

As with most predominantly European species, Cyclamen species are under pressure from habitat reduction. All species of Cyclamen are listed in Appendix II of the CITES of Wild Fauna and Flora (www.cites.org), and thus receive some level of protection from wild collection. If protection of the species is to be effective, it is important to know how rapidly changing climate might affect Cyclamen in the wild.

\subsubsection{Ecological niche models}

It has long been accepted that climate creates boundaries to species distribution (Ricklefs and Latham, 1992; Inouye, 2000; Martínez-Meyer et al., 2004a; Peterson 


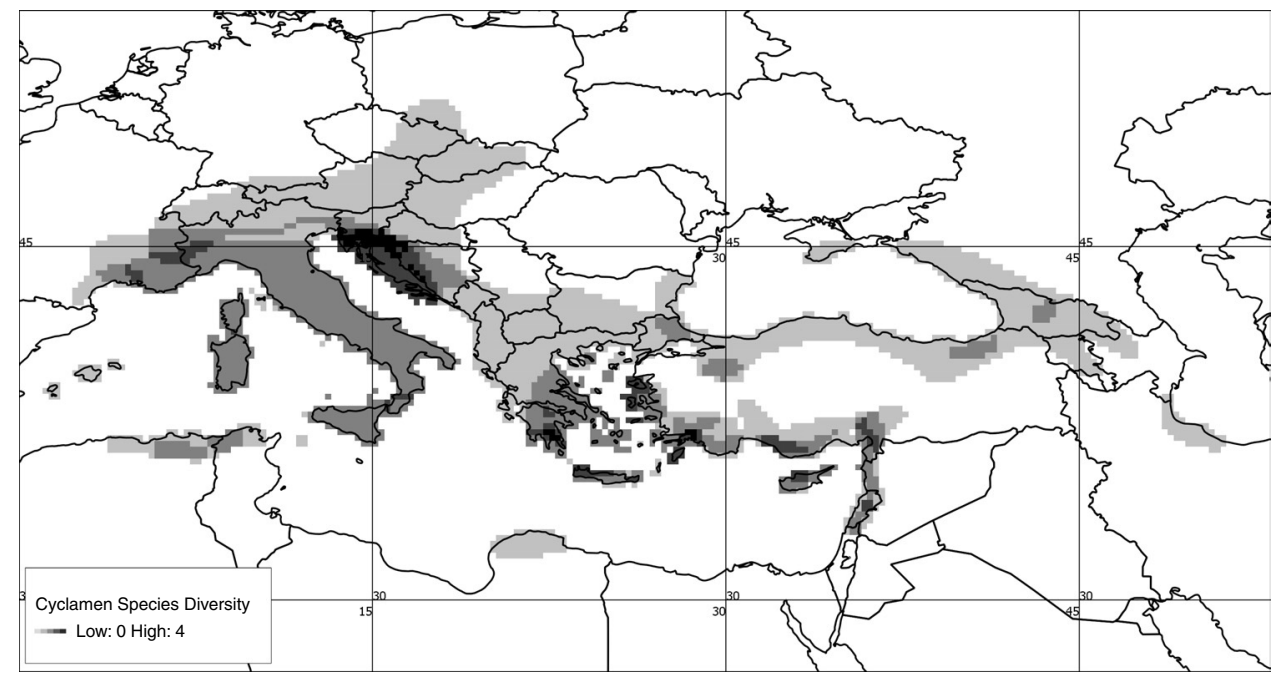

Figure 12.1 Cyclamen species diversity. Grid shows decimal degrees. Distribution data from Grey-Wilson (2003).

et al., 2005). There are many methodological applications that attempt to model the environmental preferences of species and use these to establish the environmental limits of species distribution (Nix, 1986; Guisan and Zimmermann, 2000; Guisan and Thuiller, 2005; Elith et al., 2006; Phillips et al., 2006). While individual techniques have been subject to criticism, the general technique of environmental niche modelling has been used widely for predicting species distributions (such as for invasive species - Peterson, 2003), predicting ancestral areas of extant species (Graham et al., 2004), and predicting species most likely to be threatened by climate change (Culham and Yesson, Chapter 10).

\subsubsection{An evolutionary perspective}

There have been successful efforts to extend the scope of these models to estimate historical geographic distributions by examining the models for extant species in relation to palaeoclimatic data from the Pleistocene (Hugall et al., 2002; Bonaccorso et al., 2006). This technique of historical area prediction has been tested with reference to the fossil record, and shown to predict fossil distributions successfully (Martínez-Meyer et al., 2004a). These studies demonstrate the longterm stability of species' climate preference. A logical next step is to look at longerterm stability of climate preferences on evolutionary/geological timescales. There is some evidence supporting phylogenetic niche conservatism and ecological niche heritability (Ackerly, 2003; Wiens and Donoghue, 2004; Hoffmann, 2005). Peterson et al. (1999) suggest that bioclimatic envelopes are statistically more similar among sister species in a range of animal taxa and that they are conserved 
across evolutionary time. This contention was supported by Martínez-Meyer et al. (2004b), who used species-level bioclimatic models to predict effectively the distribution of sister species of birds.

\subsubsection{Ancestral areas}

Ancestral niches have been modelled successfully by combining climatic preference data with phylogenetic trees using techniques of ancestral state reconstruction (Yesson and Culham, 2006a). The technique combining phylogenetic reconstruction and niche modelling is termed 'phyloclimatic modelling'. Yesson and Culham (2006a) recreated ancestral niches for lineages of Drosera (Droseraceae) and used a dated molecular phylogeny to select appropriate timeframes to examine these models within palaeoclimate reconstructions. They then estimated ancestral areas for Drosera lineages within the late Miocene of Australia and New Zealand.

Historically there has been a lot of interest in identifying ancestral areas and areas of prehistoric species diversity (Page, 1988; Morrone and Crisci, 1995). Perhaps the most popular technique for ancestral area reconstruction has been dispersal-vicariance analysis (DIVA - Ronquist, 1997). For DIVA, 'speciation is assumed to subdivide the ranges of widespread species into vicariant components; the optimal ancestral distributions are those that minimise the number of implied dispersal and extinction events' (Ronquist, 1997). DIVA and phyloclimatic modelling present alternative techniques for ancestral area reconstruction, but as yet there has been no comparison of these techniques.

Here we present an example of phyloclimatic modelling on Cyclamen, to gain a better understanding of ecological and evolutionary patterns for the past and future. The ancestral areas estimated by phyloclimatic modelling and DIVA are presented for comparison.

\subsection{Future distribution of Cyclamen}

Given the climatic specialisation of Cyclamen species, it is important to know how predicted climate change will affect these plants. Yesson and Culham (2006b) examined the climatic preferences of 21 Cyclamen species based on present-day distribution data, using annual and seasonal variations of climatic variables of temperature and precipitation. They found, using a randomisation test on the quantitative convergence index, that 8 out of 14 climatic variables displayed significant phylogenetic conservancy, but that within the genus climate specialisation ran from widely tolerant generalists (Cyclamen coum Mill. and C. hederifolium Alt.) through to Mediterranean specialists (C. creticum (Dörfl.) Hildebr. and C. cyprium Kotschv). These data were used to develop ecological niche models for each species 
using BIOCLIM (Busby, 1991) and Maxent (Phillips et al., 2006) algorithms. The majority of niches were isolated from each other, suggesting that species are climatically isolated, with the exception of the climatically tolerant species, whose niches were found to wholly encompass those of the more specialist species.

These niches were projected into a mid-severity future climate scenario for 2050 (scenario A2c), to examine whether areas presently occupied by Cyclamen species will be climatically suitable in the future. Except for the few species showing wide climatic tolerance, Yesson and Culham (2006b) found that for the BIOCLIM models the majority of species would be under severe threat from climate change, with 11 species predicted to have no climatically suitable area within their present range in 2050 (Fig 12.2). They noted a positive correlation of present-day range with proportion of area lost. The Maxent models (Fig 12.2) were less dramatic, but still predicted significant area loss for many species and indicated no relationship between present-day range and proportion of area lost. However, the models both indicate that areas outside the native ranges of many species are, or will become, climatically suitable.

There is some empirical evidence to support changes in geographic distribution of Cyclamen resulting from recent climate change (e.g. Fig 12.3). The climatically

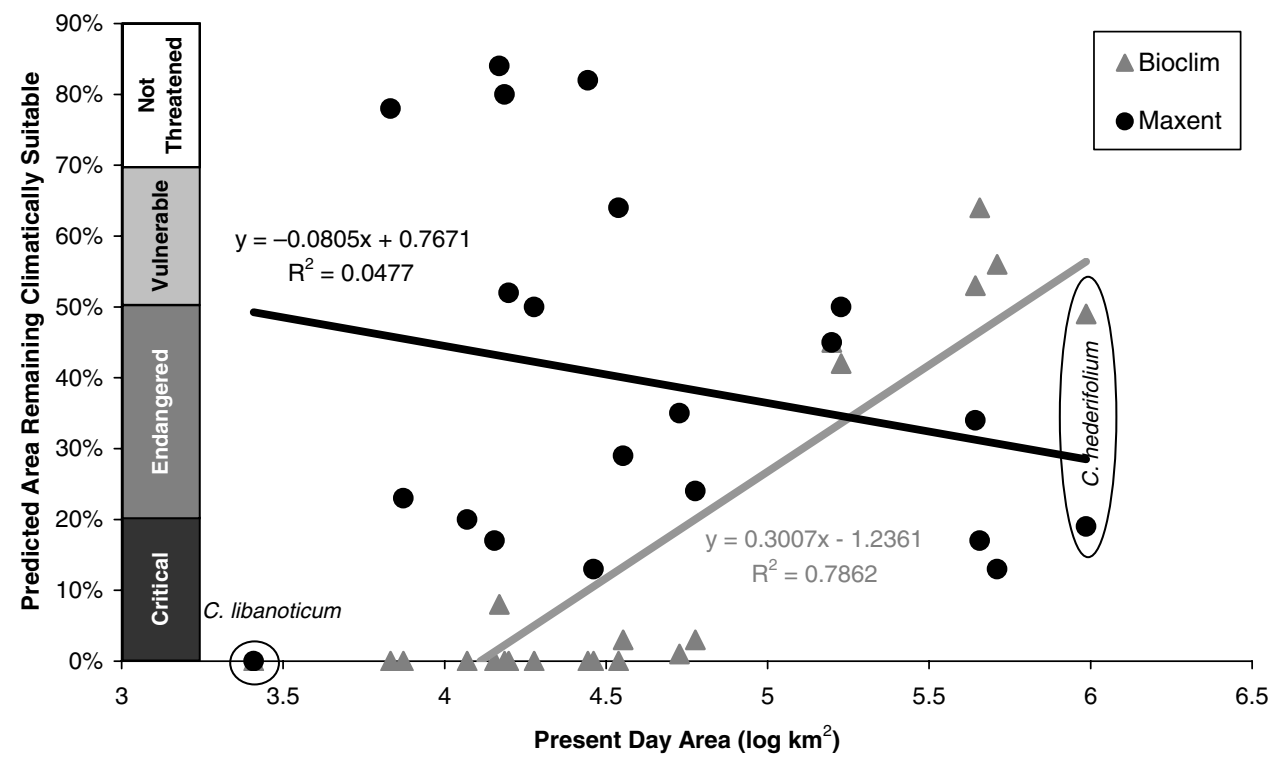

Figure 12.2 Projected area loss for Cyclamen species in 2050 using Maxent and BIOCLIM niche models. Lines show linear regression, with line equations and $r^{2}$ values adjacent. Bars to the right of the $y$-axis signify risk status based on International Union for Conservation of Nature (IUCN) classifications. Reproduced with permission from Yesson and Culham (2006a). 


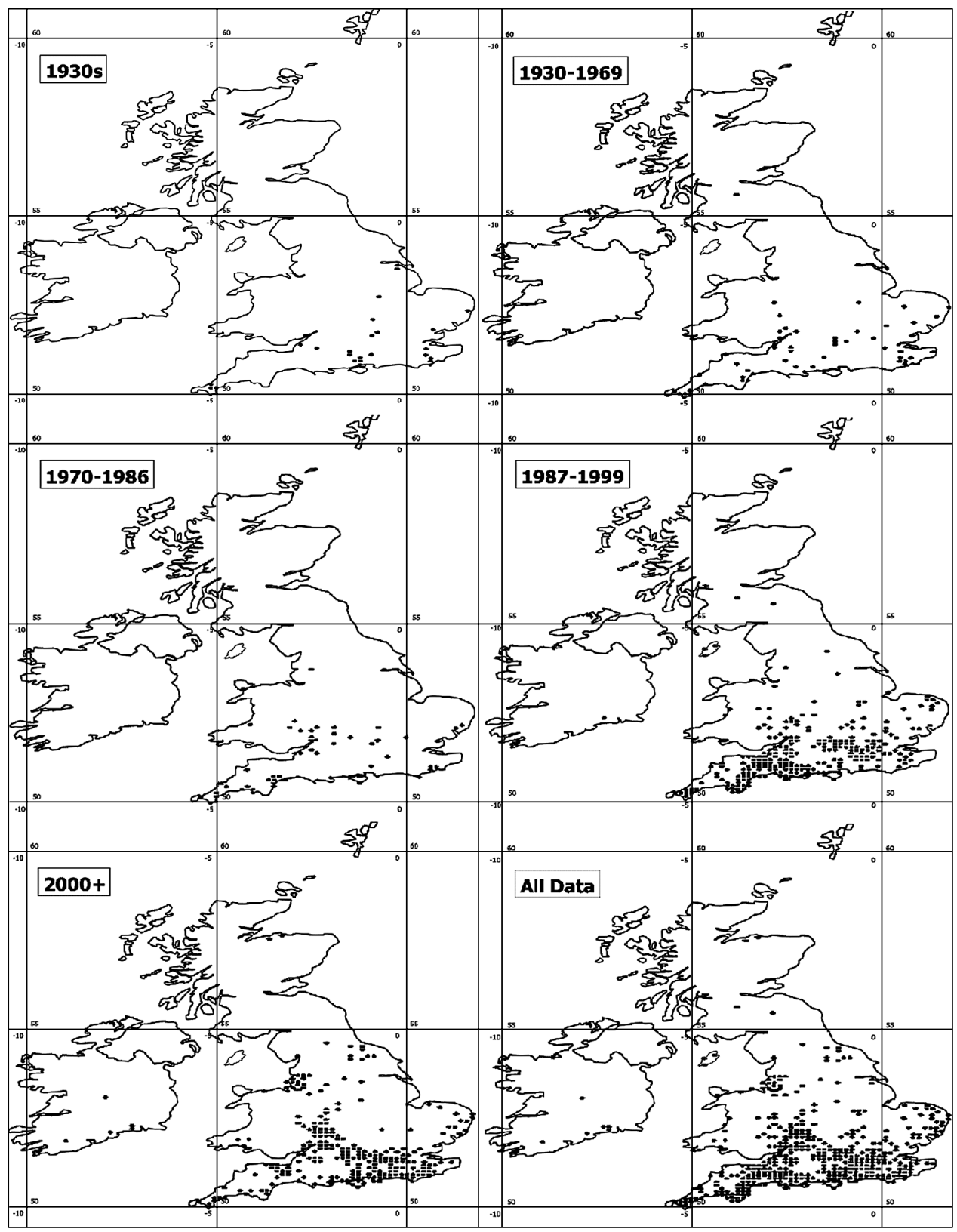

Figure 12.3 Distribution data recorded for C. hederifolium in the British Isles. New records over the past century (data from www.bsbimaps.org.uk). Grid shows decimal degrees. 
tolerant species $C$. hederifolium, although native in central and southern Europe only, has spread northwards over the past few decades of warming (Stace, 1997). The niche models, based on native distribution patterns, suggest that northern Europe should be climatically suitable for this species. This is confirmed by Botanical Society of the British Isles (BSBI) distribution data, which indicate that C. hederifolium has become naturalised and has spread its range northwards in the UK over the past century (Fig 12.3). This northward migration shows distributional changes of the scale of hundreds of kilometres within several decades and is unlikely to be due to natural dispersal, as ant-based seed dispersal events are typically 0-10 m per year (Ness et al., 2004). Plant migration rates of $10-40 \mathrm{~km}$ per 100 years have been proposed for some tree species (Davis and Shaw, 2001; McLachlan et al., 2005). It is therefore considered highly unlikely that the ant-dispersed seeds of Cyclamen would exceed this migration rate. However, C. hederifolium and C. coum are highly popular garden plants, and gardeners may have unwittingly spread these plants throughout habitats that could become important areas for conservation as native areas become climatically unsuitable.

Yesson and Culham (2006b) tested their categorisations of extinction risk from a phylogenetic perspective, but reported no significant phylogenetic pattern of phylogenetic conservancy (Fig 12.4A). However, this result is somewhat dependent upon the choice of phylogeny. Figure 12.4B shows a revised topology (Yesson et al., 2009), based on increased sampling for both subspecific taxa and molecular character data. Superficially, there appears to be a pattern of conservancy of risk, but this is marginally short of being statistically significant $(0.05$ $<p<0.1$ ) using a randomisation test of phylogenetic conservancy (Yesson and Culham, 2006b). The expectation that extinction risk based on climatic niches should show phylogenetic conservatism follows directly from the findings of phylogenetic conservatism of climatic characteristics, but for Cyclamen this is not the case.

\subsection{Past distribution and biogeography of Cyclamen}

The phylogenetic heritability of climatic preference and extinction risk for Cyclamen suggests that evolutionary history is an important factor in understanding the impact of climate change. Climatic conditions are inextricably linked with location, so understanding biogeography is an important step in this process.

Cyclamen species are currently restricted in their distribution. Their combined ranges cover approximately 2.25 million $\mathrm{km}^{2}$, which is about the area of Western Australia (Fig 12.1), and many species have overlapping ranges; 38\% of the quarter-degree squares contain more than one species. However, the majority of range overlap is accounted for by the few wide-ranging species (C. coum, C. hederifolium, 
A

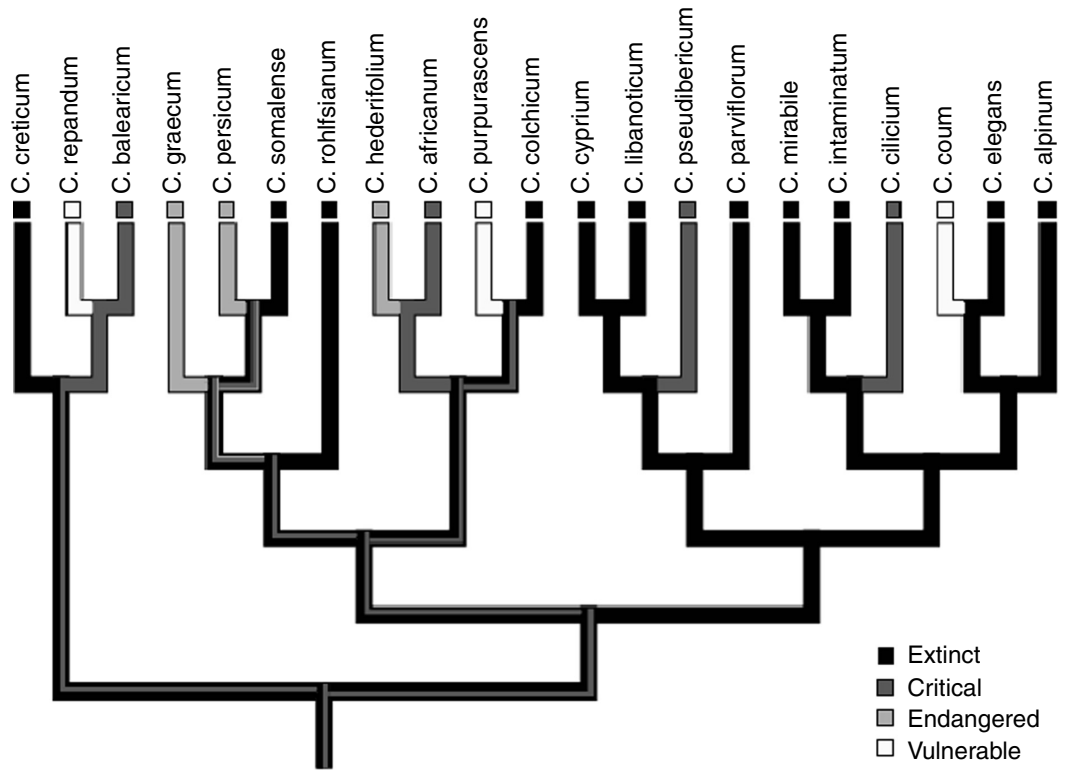

B

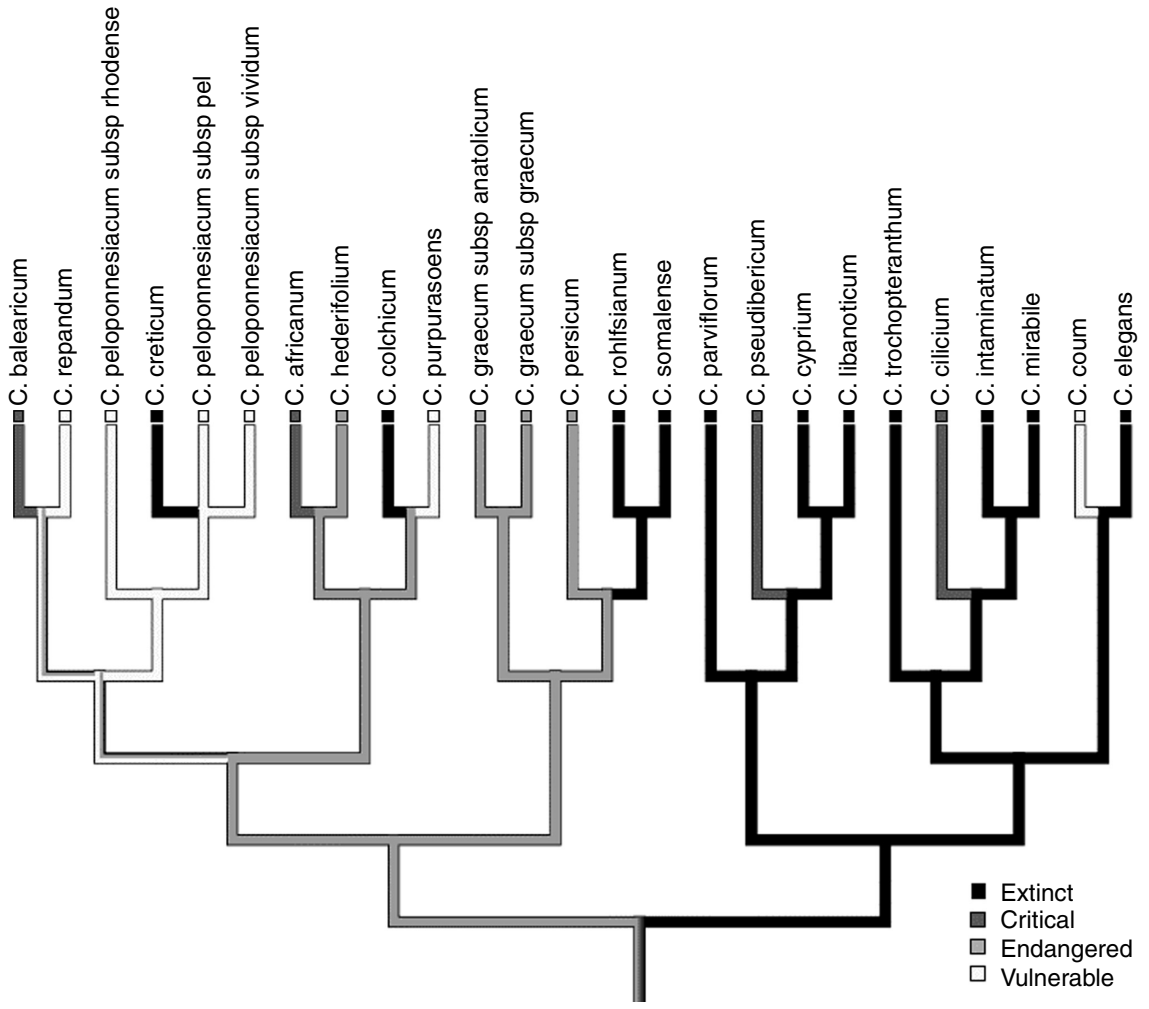

Figure 12.4 Parsimony optimisation of extinction risk for Cyclamen. Parsimony optimisation of extinction risk based on examination of models within 2050 scenario for BIOCLIM niche models (Yesson and Culham, 2006a). (A) Species-level phylogeny from Yesson and Culham (2006a). (B) Alternative topology, including subspecific sampling (Yesson et al., 2009). Risk categories are based on the proportion of area lost using the IUCN Red List categories. Note that risk value classification for species and subspecies is the same. 
Table 12.1 Vicariance events proposed for Cyclamen that have been identified with reported geological events. From Yesson et al. (2009).

\begin{tabular}{|c|c|c|c|}
\hline Epoch & Clade area 1 & Clade area 2 & Geological event \\
\hline $\begin{array}{l}\text { Mid-Late } \\
\text { Miocene }\end{array}$ & $\begin{array}{l}\text { C. mirabile- } \\
\text { C. parviflorum Eastern } \\
\text { Europe and Asia }\end{array}$ & $\begin{array}{l}\text { C. creticum- } \\
\text { C.graecum Western } \\
\text { Europe }\end{array}$ & $\begin{array}{l}\text { East/West European } \\
\text { Divergence } \\
\text { (Oberprieler, 2005) }\end{array}$ \\
\hline $\begin{array}{l}\text { Early-Mid } \\
\text { Pliocene }\end{array}$ & $\begin{array}{l}\text { C. purpurascens + } \\
\text { C. colchicum } \\
\text { Eastern Europe }\end{array}$ & $\begin{array}{l}\text { subgen. Psilanthum } \\
\text { Western Europe }\end{array}$ & $\begin{array}{l}\text { East/West European } \\
\text { Divergence } \\
\text { (Oberprieler, 2005) }\end{array}$ \\
\hline $\begin{array}{l}\text { Late } \\
\text { Miocene }\end{array}$ & $\begin{array}{l}\text { C. somalense } \\
\text { Somalia }\end{array}$ & $\begin{array}{l}\text { C. rohlfsianum }+ \\
\text { C. persicum North } \\
\text { Africa }\end{array}$ & $\begin{array}{l}\text { Formation of Sahara } \\
\text { (Douady et al., 2003) }\end{array}$ \\
\hline $\begin{array}{l}\text { Mid } \\
\text { Pliocene }\end{array}$ & $\begin{array}{l}\text { C. hederifolium } \\
\text { Europe }\end{array}$ & C. africanum Africa & $\begin{array}{l}\text { Loss of Tyrrhenian } \\
\text { land bridge } \\
\text { (Estabrook, 2001) }\end{array}$ \\
\hline
\end{tabular}

C. purpurascens Mill. and C. repandum $\mathrm{Sm}$.), and no more than four species can be found in any one quarter-degree square.

Yesson et al. (2009) examined Cyclamen distribution patterns from a phylogenetic perspective and found that no pair of sister species overlapped in range, with the exception of $C$. balearicum Wilk. and C. repandum in a small area of southern France. Such allopatry, coupled with the ease of hybridisation between closely related species, implies a pattern of allopatric speciation in the evolutionary development of Cyclamen.

Assuming that allopatric speciation enables identification of patterns of vicariance and dispersal that best fit the observed distributions and reconstructed phylogeny, Yesson et al. (2009) used DIVA to identify 19 dispersal and 11 vicariance events in the evolutionary development of Cyclamen. Notably, there were four vicariance events coinciding with reported geological patterns elsewhere in the literature (Table 12.1). However, the majority of proposed vicariance events were not coupled with recognised geological patterns. One explanation for this might be climatic differentiation, which could help to explain the distinct climatic niches of extant species. The DIVA reconstruction was unable to discriminate between any of the areas of the present distribution at the root of the phylogenetic tree, and therefore the ancestral area for Cyclamen was estimated as the full extent of all extant Cyclamen species.

However, the niche model for the ancestral Cyclamen developed by Yesson and Culham (2006a), together with a phyloclimatic modelling approach, can be used to provide an alternative hypothesis of ancestral area (see Culham and Yesson, Chapter 10). This model was projected into a palaeoclimate reconstruction of the 


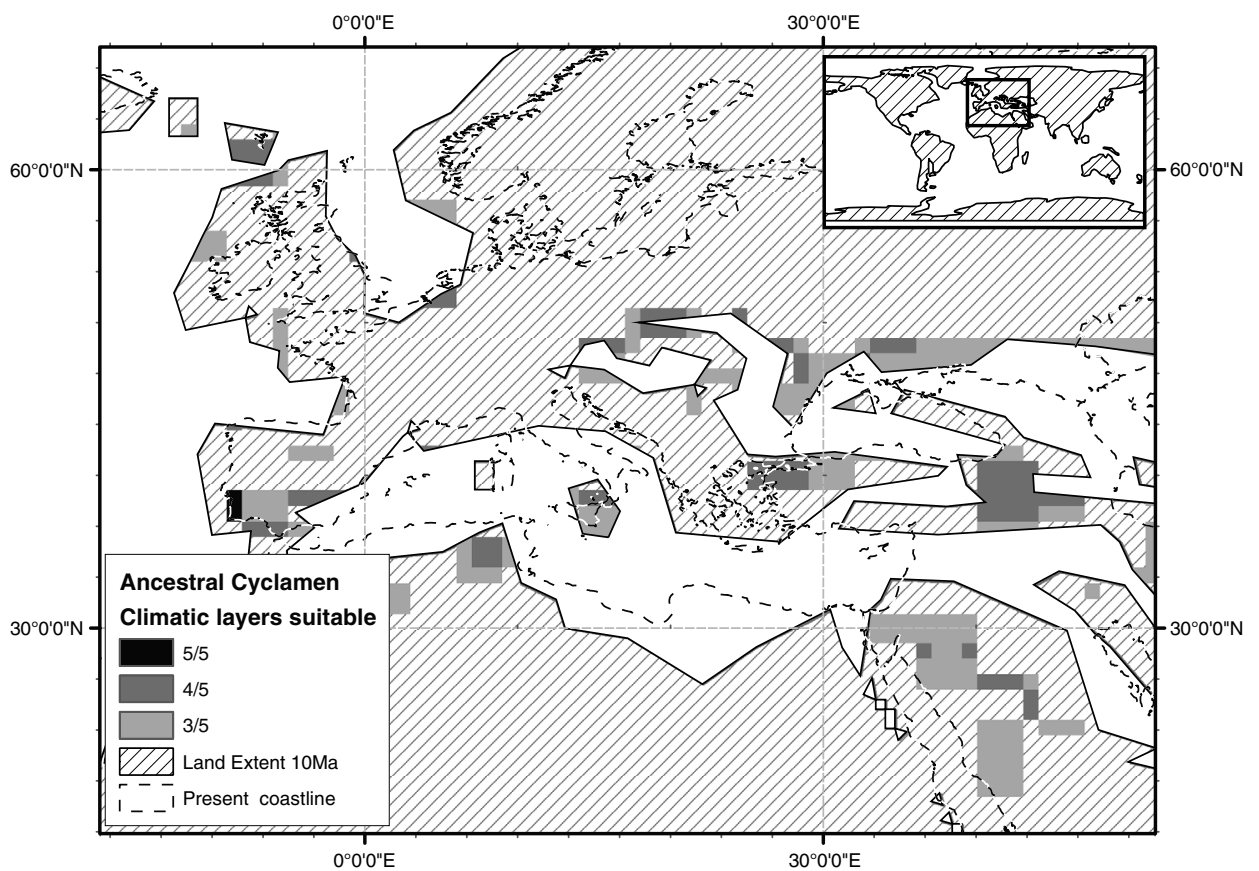

Figure 12.5 Area prediction for the ancestral Cyclamen in the late Miocene around the Mediterranean basin. Niche model developed by Yesson and Culham (2006a), projected using the BIOCLIM 'OR' methodology (Piñeiro et al., 2007), implemented in openModeller as the 'Envelope Score' algorithm. Reproduced with permission from Yesson (2008).

mid-late Miocene, which is the age of the ancestral lineage determined by the molecular dating of Yesson et al. (2009). Figure 12.5 demonstrates the climatically suitable areas for the ancestral Cyclamen for the mid-Miocene, and shows that a very small proportion of the extant range for all Cyclamen species would have been climatically suitable; these lie in what is now northern Turkey, North Africa and southern Iberia. In this case, the areas selected are a subset of the areas selected by DIVA. However, the geography of the Mediterranean at this time was very different from the present (Krijgsman, 2002). For example, the Italian peninsula was not formed at this time. To understand why the different methods vary we need to discuss their properties.

\subsection{Potential of ancestral area reconstruction based on the reconstruction of ancestral niche}

DIVA is a popular method for ancestral area reconstruction (Ronquist, 1997; Sanmartin, 2003; Oberprieler, 2005). The first step is to partition observed 
distributions into areas of endemism (Ronquist, 1997). These areas are chosen as being limited by geographical boundaries that may have acted as barriers to dispersal (Oberprieler, 2005). This partitioning is a somewhat arbitrary process, relying on the subjective decision of the individual researcher, and may present problems of circular logic if assumptions of dispersal ability are made prior to an analysis of dispersal. DIVA uses a cost-based model of dispersal and vicariance to reconstruct present-day observed areas onto internal nodes of a phylogeny (Ronquist, 1997). Clearly, if the true ancestral area was outside the present range, then DIVA cannot select the true area. Neither can such an approach discriminate between geographic regions that did not exist at the time of ancestral evolution. Furthermore, such analysis takes no account of the environment of the area at the time, and though the area selected may be climatically suitable for some species at present, it may not have been suitable during relevant periods of the past.

Ancestral area selection based on the reconstruction of the ancestral niche is a viable alternative to DIVA. It can construct independent hypotheses of potential distribution. As such it can be used as a complementary technique to refine area selection. It is a data-driven approach that does not rely on the subjective preselection of areas. Nor is it restricted analytically in the number of areas that it can consider. The underlying assumption is that of niche persistence and heritability.

Current research in ancestral area selection is focused on integrating probabilities of dispersal, but these methods still require initial partitioning of areas. For example, the program Lagrange uses a likelihood model to reconstruct ancestral areas and integrates dispersal probabilities by pre-assigning these probabilities based on hypotheses of the presence or absence of geographic barriers at any given time (Ree et al., 2005).

\subsection{Conclusions}

Phyloclimatic modelling does not integrate models of dispersal. This is an avenue for further development. One approach might be to track continuously, or at least at frequent intervals, the niches over the evolutionary timescales, which could theoretically show the potential for gradual migration through climatically suitable areas or reject such a theory by showing the need for long-distance dispersal. Unfortunately, we do not yet have continuous palaeoclimate reconstructions of appropriate resolution spanning the millions of years required for such analysis. This means that we are always likely to see predictions for different timeframes that do not spatially overlap, which presents difficulties in deciding between models of gradual migration or long-distance dispersal. Furthermore, the appearance of intermediate areas with suitable environments does not discount the hypothesis that a long-distance dispersal event could have bypassed this area. 
Such a hypothesis could only be rejected by the discovery of fossil evidence in the intermediate areas, but the paucity of the fossil record often makes such testing impossible.

Climate change has already affected the distribution of Cyclamen species, and this seems likely to continue if predicted rates of warming prove accurate. Although niche modelling has met some criticism (see Rödder et al., Chapter 11), it is still a useful tool in the understanding, the prediction and ultimately the amelioration of the negative impacts of climate change. We have seen that phyloclimatic modelling approaches that take into account evolutionary perspectives can provide a deeper understanding of environmental niches, and how these can or cannot change over time. They can also be used to assess extinction risk. When we have insufficient data for traditional methods of extinction-risk estimation, phylogenetic relatedness to species of known risk might be employed as a useful proxy.

In the case of Cyclamen there is no significant pattern of phylogenetic relatedness, but if a new species was discovered in section Gyropheobe, then it would seem appropriate to regard it as being at high risk, as most closely related species are at high risk. This may provide a useful interim rapid assessment until a more rigorous process can be accomplished.

\section{Acknowledgements}

We wish to thank the Biotechnology and Biological Sciences Research Council for funding the BioDiversity World project (45/BEP17792), the University of Reading for funding the first author's $\mathrm{PhD}$, and numerous colleagues for feedback and discussion of our ideas over the past five years.

\section{References}

Ackerly, D. D. (2003). Community assembly, niche conservatism, and adaptive evolution in changing environments. International Journal of Plant Sciences, 164, S165-S184.

Anderberg, A. A. (1994). Phylogeny and subgeneric classification of Cyclamen

L. (Primulaceae). Kew Bulletin, 49, 455-467.

Anderberg, A. A., Trift, I. and Källersjö, M. (2000). Phylogeny of Cyclamen

L. (Primulaceae): evidence from morphology and sequence data from the internal transcribed spacers of nuclear ribosomal DNA. Plant Systematics and Evolution, 220, 147-160.

Bennett, S. T. and Grimshaw, J. M. (1991). Cytological studies in Cyclamen subg. Cyclamen (Primulaceae). Plant Systematics and Evolution, 176, 135-143.

Bonaccorso, E., Koch, I. and Peterson, A. T. (2006). Pleistocene fragmentation of 
Amazon species' ranges. Diversity and Distributions, 12, 157-164.

Busby, J. R. (1991). BIOCLIM: a bioclimatic analysis and prediction system. In Nature Conservation: Cost Effective Biological Surveys and Data Analysis, ed. C. R. Margules and M. P. Austin. Melbourne: CSIRO, pp. 64-68.

Clennett, J. C. B. (2002). An analysis and revision of Cyclamen L. with emphasis on subgenus Gyrophoebe O. Schwarz. Botanical Journal of the Linnean Society, 138, 473-481.

Compton, J. A., Clennett, J. C. B. and Culham, A. (2004). Nomenclature in the dock. Overclassification leads to instability: a case study in the horticulturally important genus Cyclamen (Myrsinaceae). Botanical Journal of the Linnean Society, 146, 339-349.

Culham, A., Denney, M., Jope, M. and Moore, P. (2009). A new species of Cyclamen from Crete. Cyclamen, $\mathbf{3 3}$, 12-15.

Davis, M. B. and Shaw, R. G. (2001). Range shifts and adaptive responses to Quaternary climate change. Science, 292, 673-679.

Debussche, M., Garnier, E. and Thompson, J. D. (2004). Exploring the causes of variation in phenology and morphology in Mediterranean geophytes: a genus-wide study of Cyclamen. Botanical Journal of the Linnean Society, 145, 469-484.

Douady, C. J., Catzeflis, F., Raman, J., Springer, M. S. and Stanhope, M. J. (2003). The Sahara as a vicariant agent, and the role of the Miocene climatic events, in the diversification of the mammalian order Macroscelidae (elephant shrews). Proceedings of the National Academy of Sciences of the USA, 100, 8325-8330.
Elith, J., Graham, C. H., Anderson, R. P. et al. (2006). Novel methods improve prediction of species' distributions from occurrence data. Ecography, 29, 129-151.

Estabrook, G. F. (2001). Vicariance or dispersal: the use of natural historical data to test competing hypotheses of disjunction on the Tyrrhenian coast. Journal of Biography, 28, 95-103.

Gielly, L., Debussche, M. and Thompson, J. D. (2001). Geographic isolation and evolution of Mediterranean endemic Cyclamen: insights from chloroplast trnL (UAA) intron sequence variation. Plant Systematics and Evolution, 230, 75-88.

Graham, C. H., Ron, S. R., Santos, J. C., Schneider, C. J. and Moritz, C. (2004). Integrating phylogenetics and environmental niche models to explore speciation mechanisms in dendrobatid frogs. Evolution, 58, 1781-1793.

Grey-Wilson, C. (2003). Cyclamen: a Guide for Gardeners, Horticulturalists and Botanists. London: Batsford.

Guisan, A. and Thuiller, W. (2005). Predicting species distribution: offering more than simple habitat models. Ecology Letters, 8, 993-1009.

Guisan, A. and Zimmermann, N. E. (2000). Predictive habitat distribution models in ecology. Ecological Modelling, 135, 147-186.

Hoffmann, M. H. (2005). Evolution of the realized climatic niche in the genus Arabidopsis (Brassicaceae). Evolution, 59, 1425-1436.

Hugall, A., Moritz, C., Moussalli, A. and Stanisic, J. (2002). Reconciling paleodistribution models and comparative phylogeography in the wet tropics rainforest land snail Gnarosophia bellendenkerensis 
(Brazier 1875). Proceedings of the National Academy of Sciences of the USA, 99, 6112-6117.

Inouye, D. W. (2000). The ecological and evolutionary significance of frost in the context of climate change. Ecology Letters, 3, 457-463.

Krijgsman, W. (2002). The Mediterranean: mare nostrum of earth sciences. Earth and Planetary Science Letters, 205, 1-12.

Martínez-Meyer, E., Peterson, A. T. and Hargrove, W. W. (2004a). Ecological niches as stable distributional constraints on mammal species, with implications for Pleistocene extinctions and climate change projections for biodiversity. Global Ecology and Biogeography, 13, 305-314.

Martínez-Meyer, E., Peterson, A. T. and Navarro-Siguenza, A. G. (2004b). Evolution of seasonal ecological niches in the passerina buntings (Aves: Cardinalidae). Proceedings of the Royal Society of London B, 271, 1151-1157.

McLachlan, J. S., Clark, J. S. and Manos, P. S. (2005). Molecular indicators of tree migration capacity under rapid climate change. Ecology, 86, 2088-2098.

Morrone, J. J. and Crisci, J. V. (1995). Historical biogeography: introduction to methods. Annual Review of Ecology and Systematics, 26, 373-401.

Ness, J. H., Bronstein, J. L., Andersen, A. N. and Holland, J. N. (2004). Ant body size predicts dispersal distance of antadapted seeds: implications of smallant invasions. Ecology, 85, 1244-1250.

Nix, H. A. (1986). A biogeographic analysis of Australian elapid snakes. In Atlas of Elapid Snakes of Australia, ed. R. Longmore. Canberra: Australian Government Publishing Service, pp. 4-15.
Oberprieler, C. (2005). Temporal and spatial diversification of circumMediterranean CompositaeAnthemideae. Taxon, 54, 951-966.

Page, R. D. M. (1988). Quantitative cladistic biogeography constructing and comparing area cladograms. Systematic Zoology, 37, 254-270.

Peterson, A. T. (2003). Predicting the geography of species' invasions via ecological niche modeling. Quarterly Review of Biology, 78, 419-433.

Peterson, A. T., Soberón, J. and SánchezCordero, V. (1999). Conservation of ecological niches in evolutionary time. Science, 285, 1265-1267.

Peterson, A. T., Tian, H., MartínezMeyer, E. et al. (2005). Modeling distributional shifts of individual species and biomes. In Climate Change and Biodiversity, ed. T. E. Lovejoy and L. J. Hannah. New Haven, CT: Yale University Press, pp. 211-229.

Phillips, S. J., Anderson, R. P. and Schapire, R. E. (2006). Maximum entropy modeling of species geographic distributions. Ecological Modelling, 190, 231-259.

Piñeiro, R., Aguilar, J. F., Munt, D. D. and Feliner, G. N. (2007). Ecology matters: Atlantic-Mediterranean disjunction in the sand-dune shrub Armeria pungens (Plumbaginaceae). Molecular Ecology, 16, 2155-2171.

Ree, R. H., Moore, B. R., Webb, C. O. and Donoghue, M. J. (2005). A likelihood framework for inferring the evolution of geographic range on phylogenetic trees. Evolution, 59, 2299-2311.

Ricklefs, R. E. and Latham, R. E. (1992). Intercontinental correlation of geographical ranges suggests stasis in ecological traits of relict genera of temperate perennial herbs. American Naturalist, 139, 1305-1321. 
Ronquist, F. (1997). Dispersal-vicariance analysis: a new approach to the quantification of historical biogeography. Systematic Biology, 46, 195-203.

Sanmartin, I. (2003). Dispersal vs. vicariance in the Mediterranean: historical biogeography of the Palearctic Pachydeminae (Coleoptera, Scarabaeoidea). Journal of Biogeography, 30, 1883-1897.

Stace, C. (1997). New Flora of the British Isles, 2nd edn. Cambridge: Cambridge University Press.

Wiens, J. J. and Donoghue, M. J. (2004). Historical biogeography, ecology and species richness. Trends in Ecology and Evolution, 19, 639-644.
Yesson, C. (2008). Investigating plant diversity in Mediterranean climates. Unpublished PhD thesis, University of Reading.

Yesson, C. and Culham, A. (2006a). Phyloclimatic modelling: combining phylogenetics and bioclimatic modelling. Systematic Biology, 55, 785-802.

Yesson, C. and Culham, A. (2006b). A phyloclimatic study of Cyclamen. BMC Evolutionary Biology, 6, 72.

Yesson, C., Toomey, N. H. and Culham, A. (2009). Cyclamen: time, sea and speciation biogeography using a temporally calibrated phylogeny. Journal of Biogeography, 36, 1234-1252. 